ligible to the English reader. It deserves some attention, because it is supposed to account for the practice of the actual and the potential cautery. Each important spot along the course of the internal vessels just described has its peculiar designation; and hence the native physiology and anatomy serve as guides to the surgical operator as they do among us. The difference lies in this, that the anatomy of the Chinese is chiefly confined to the surface, while ours never fails to guide the surgeon in exploring the very recesses of the human system.

The lower figure* on the right is the fœetus, with a black cap, which is meant for a representation of the placenta; the figures $\uparrow$ just above the foetus are the large and small intestines.

\section{ANEURISM OF THE AORTA.}

\section{To the Editor of The LanceT.}

Sir:-Should the following case, and remarks, be deemed worthy of a place in your Journal, I shall feel obliged by their insertion, having the honour to remain, Sir, your most obedient servant,

$$
\text { John GaY, }
$$

Surgeon to the Royal Free Hospital, to the Provident Clerks' Association, Asylum for the Houseless, \&c.

12, Pavement, Finsbury,

January 11, 1841.

John Scott, ætat 28.-A little man, with red hair, and other indications of a scrofalous coustitution, was admitted into the Royal Free Hospital on the 25th of Marcb. He stated that he had worked for some years at Liverpool, as an anchor-wright, but that at Christmas he was thrown out of employment; he was obliged, consequently, to wander about, in search of work, during the most inclement part of the winter, barely clad, and as badly fed; and to the sufferings which he thus endured, from cold and want, he attributes his present complaints. About three weeks before be arrived in London, he perceived the first symptoms of indisposition, which consisted in an almost frostbitten state of the lower extremities, cough, and slight dyspnoea, succeeded by uneusiness about the chest, expectoration tinged with blood, and occasional epistaxis. These symptoms increased, and, shortly afterwards, a small tumour (without pain) made its appearance on the right side of the sternum. In this state of extreme wretchedness he applied for admission at the Asylum for the Houseless Poor, and was thence sent to the Royal Free Hospital; he was there put

\section{* Fig. 4.}

$\uparrow$ Figs. 2 and 3. into a warm batb, and I saw him immediately after.

March 25. After a bath, skin hot and perspiring; lips purple; breathes with difficulty, and expectorates a considerable quantity of mucus, tinged with blood; pulse 110, small, but with a slight jerk; unable to lie on the left side, a posture which gives him severe pain about the right hypochondriac region; tongue rather white; no appetite.

On the right of the sternum, and between the cartilages of the first and second ribs, is a pulsating tumour, about the size of a walnut; the skin covering it is slightly inflamed; yields on pressure, as though fluid were confined beneath, and appears to be very thin; if it be pressed but ever so gently, the patient complains of severe pain extending itself towards the right axilla. The pulsation in the tumour is both beard and felt to be the same precisely as that of the heart, and without the brnissement that aneurismal tumours generally yield; the sounds of the heart itself are heard more distinctly, and its impulse is more violent on the right than on the left side of the sternum, and most especially on the apex of the tumour; the arteries of the wrists have no sensible difference in their action; and the same is observable of the carotids. There is, however, a considerable retrocession of blood into the right jugular synchronous with each ventricular systole.

The respiratory murmur is londer on the left side of the chest than on the right, where it is probably obscured by some large crepitation, which is diffused over the whole of that side, but only to be heard behind. Owing to the embarrassed condition of his breathing, and the pain which he experiences from any movement, I am not able to obtain any further auscultatory evidences. I ordered twenty leeches to be applied to the chest, and prescribed the following me. dicine :-

\section{R Tincture of digitalis, $\mathrm{M} 12$;}

Antimonial wine, 3 ss ;

Solution of acetate of ammonia, 3 जs:

Sulphate of magnesia, $3 \mathrm{j}$;

Camphor mixture, 3 j.

Mix this for a draught, to be taken every four hours.

26. Has passed a comfortable night; cough not so violent, and the expectoration presents no traces of blood, consisting chiefly of frothy mucus; bowels relieved; pulse still jerking slightly. Twelve leeches to be applied to the chest; the dranghts to be continued.

27. Skin hot ; perspired freely during the night; rest disturbed by unpleasant dreams; felt much relief from the bleeding; other symptoms more favourable; pulse, 96 , moderate. 
R Antimonial uine, $3 \mathrm{ss}$;

Tincture of digitalis, M 12 ;

Compound tincture of comphor, $\mathrm{M} \times \mathrm{xv}$; Water, $\overline{\mathrm{j}} \mathrm{j}$.

To be taken every four hours; and three grains of mercury, with chalk, at bed-time.

30. Has continued his remedies, with much relief; but this morning he com. plains of nausea and vertigo; pulse 90, and feeble. Continue the draghts without the antimony wine.

April 2. Expresses himself as being "very comfortable ;" but the tumour has become more prominent, and larger at the base.

On exploring the chest to-day, I find that the sounds of the heart are heard, and its impulse felt more forcibly on the site of the tumour than on any other part of the chest. A slight bruissement accompanied the first sound, which is distinguishable only over the tumour; respiratory sounds, louder on the left side than on the right, and accompanied with some rhoncus and sybilis; very little of the moist crepitus remaining; percussion gives a dull sound over the whole of the left side : this test could not be applied to the right, on account of the uneasiness to which it would have subjected him. Continue the draughts, with 20 minims of antimonial wine; meat diet, without porter or wine.

13. Since last report, the tumour has increased considerably, and acquired a somewhat irregular surface; breathing has become perfectly tranquil whilst he remains in a state of rest, and bis cough troubles him but very slightly; sleeps well at night, but cannot lie on the left side, in any other posture, with ease; gentle pressure on the tumour gives pain, and disturbs the tranquillity of his respiration. For the last five or six days he has again complained of giddiness and tendency to faintness, and his pulse has become feeble and irregular, beating about 96 times in the minute. The abnormal sounds have quite left the chest, as far as respiration is concerned, but the vesicular murmur is still more clearly discernible on the left than on the right side; the skin covering the tumour has recovered its healthy appearance. A lotion was kept applied to the tumour, consisting of nitrate of potass and muriate of ammonia, of each $3 \mathrm{ij}$, to half a pint of water.

27. For the last three days he has complained of headach, and to-day has been sick several times. On examining the chest, I find (what I have not before noticed) a bulging of the left side of the chest, chiefly about the curratures of the fifth, sixth, and seventh ribs; no uneasiness in this region, but a dulness on percussion; in other respects as at last note.

At the surgestion of an esteemed friend, I have directed him to take the following, instead of the draughts, which appear to bave kept his circulation at a very low ebb :-

$\mathrm{R}$ Tinclure of muriate of iron, $\mathbf{M} 12$; Cimnanon zater, $\overline{3} \mathrm{j}$.

To be taken every four hours.

May 8. Complains of uneasiness in the region of the tumour, which he has felt for some days, but which, today, amounts to pain; pulse 105, with mure power; skin rather hot and feverish. Twelve leeches to be applied to the tumour, and a saline mixture, with sulphate of magnesia, to be taken every four hours.

9. Bowels well relieved; pain and excitement subdued.

13. Pain gone; complains of uneasiness in the bowels; pulse 100, moderate.

\section{$\mathrm{R}$ Tincture of digitalis, $\mathrm{M} \mathbf{2 0}$;} A romatic confection, $3 \mathrm{ss}$; Peppermint water, $\overline{3}$ iss.

To be taken every four hours.

27. The action of the heart and arteries has again become feeble and irregular; and since this state of the circulation has been again obtained, the tumour has become de. cidedly lessened in bulk; to-day I have been able to sound the right side of the chest; the degree of resonance is very feeble, and offers a striking contrast with that which the whole of the right side yields behind; respiratory murmur heard more clearly in every part of the chest, excepting around the tumour, but generally more loud on the left than on the right side; the voice reverberates considerably on the right side, and approaches in its character towards cegophony ; on the same side, behind, may be detected a bruit, accompanying the first sound of the heart.

In other respects he appears tolerably well; cough has entirely ceased, and he is enabled to sleep well; pulse weak and irregular, 100.

June 8. Better.

\section{$\mathrm{Rx}$ Tincture of digitalis, 3 viss ;}

Tincture of hyoscyamus, 3 iss.

Thirty-five drops to be taken every six hours.

12. The tumour is nearly reduced to a level with the parietes of the chest, which in that situation have become sensibly thicker; pulse accompanied with a slight jerk. Increase the number of the drops to 45 , ihree times in the day.

15. Impulse of the beart slightly increased; filst sound of the heart prolonged, and accompanied with a bruit, which can be heard most distinctly by applying the stethoscope rrtier above, and about half an inch to the left of the tumour; pulse 95, 6rm, but intermitting. Tucrease the drops to 50 , three times a day.

July 3 . The tumour has been gradually receding, and is no longer observable; the 
pulsation, however, is felt on laying the hand over the site which it occupied.

8. To.day the man left the hospital, with. out my knowledge; his breathing having become perfectly still, and every symptom so thoroughly alleviated, that he wus sure he could return to work, if he could obtain it; upon this pretext be left.

The foregoing extracts, from my notebook, include all the important points, which I was enabled to glean from an almost daily examination of this individual's case. When he came under my nofice, I was led to consider the indications which the history and aspect of his disease appeared to suggest ; and, with the aid of pathology, most valuable even in its yet infantile stage, to make them the grounds of a plan of treatment, to be rigorously pursued. It had been my lot to see many instances in which the plan of Valsalva (now practically advocated) was pursued; and, from its repeated failures, and only occasional (and that apparently haphazard) snccess; I resolved to reflect, ere I gave a patient with aneurism the chances of an alternative, but little if aught better than those of its spontaneous termination. But it is not my intention to speak disparagingly of the individual, to whose treatment of aneurism $I$ have alluded. Much credit is due, as it has been awarded, to that great man, for his courageous and happy conflicts with disease; but it is probably a matter of doubt, whether it is wise now, with the present condition of society, to imitate him in any thing but the intellectuality and profound knowledge which presided over all his procedures. The searing iron and boiling oil, which were comparatively innocuous to our more hardy ancestors, have been superseded by more mild and compatible surgery; not only as the result of that progress which surgery, in common with all other scientific discovery, has made, but as demanded by those modified conditions of the human organisation which have been brought about by the usages of an advanced era in the history of human society; so that (in my humble opinion) the argu. ments for the adoption of a certain plan of treatment, in any disease, are not established by the facts, however abundant, of its having been followed with eminent success, some century or more since. And, to my mind, this is the only way to solve a discrepancy which, unaccounted for, would render the observations of the most gifted members of our profession but of little estimation, either for the establishment of a theory, or as rules of practice. Thus, whilst Valsalva's treatment of aneurism was suppoled by the physicians of his own time, and has been since, by Guerin, Pelletan, Sabatier, and others, it has been deemed useless by Boyer, Roux, Cooper, and other masters of modern surgery.

But, besides, the blood contaius the mate- rial which is to repair the injury which an aneurismal artery has suffered. It has been said by eminent pathologists, that the fibrin. ous lamellæ contained in the sac are secreted by it; but this, I think, is not borne out by a careful examination of the concretion; at all events, if not directly, it must indirectly be a separation from the circulating fluil, and consists principally of fibrin. Now the tendency of repeated venesection is to diminish very considerably this element of the blood, and with it the disposition in that fluid to deposit a coagulum, to say nothing of the serious consequences of procured anæmia on the system at large. Hence this course does not, a priori, appear calculated to lead to a spontaneous cure of aneurism, but rather, on the other hand, to weaken our hope of such a termination, inasmuch as it wastes the muteriul, and the power by which it is applied to the reparation of the diseased and enfeebled artery. Put can a remora of the circulation be induced without such a sacrifice as blood letting necessarily involves? Can the blood be made to circulate in a pre. ternaturally languid current, and retain, at the same time, its normal quantity and proportion of ingredients? These questions I attempted to solve by the treatment of the foregoing case, and from the results am in. duced to think that the course pursued is strictly in harmony with what we know of the nature of aneurismal iumours. Throughout, this individual was kept (with the ex. ception of a short period, when the treatment was reversed) in a state bordering upon syucope, taking care not to go so far as to produce vomiting. If symptoms of bron. chitis or acute pain in the region of the tumour manifested themselves, leeches were applied, and gave very marked relief; at the same time, autriment was given to him in the form of animal broths as frequently as he was disposed to take it, and attention paid to the state of his bowels.

The situation of the aneurism in this case is a question upon which I will not venture an opinion; but $I$ felt assured in my own mind that reparation of a permanent character had taken place. My object, in the recital of this case, will be answered, should it tend to elicit facts, either confirmatory of, or hostile to, the views which led me to adopt this (not novel, but unadvocated) plan of treatment.

\section{PATHOLOGY OF PNEUMONIA.}

\section{To the Editor of THE Lancet.}

Sin:-In reading the observations of $\mathrm{Mr}$. Williams on the minute pathology of puenmonia, published in the last Number of THE LANCET (Jan. 30), several particulars which appeared deserving of remark caught my attention. 